\title{
A now rarely seen anti-reflux device: The Angelchik prosthesis
}

\author{
Jake Sloane, Sanjay Gupta
}

\section{CASE REPORT}

A 43-year-old male was presented to our upper gastrointestinal clinic with acute symptoms of reflux and dysphagia to both solids and liquids. He had undergone open anti-reflux surgery 15 years prior with the fitting of a now obsolete device-the Angelchik device. Until this episode, he had enjoyed a normal diet with well controlled gastroesophageal reflux disease (GERD) symptoms. He was listed for surgery due to the sudden onset of severe symptoms and inability to tolerate food.

No erosion or injury to the esophagus was noted. However, it was evident that the prosthesis had moved into an abnormal position causing an acquired stenosis of the lumen (Figure 1). It was removed in its entirety and an immediate laparoscopic Nissen's fundoplication was performed. The patient made an uneventful recovery from the procedure and was back to eating a normal diet within two weeks of the procedure.

\section{DISCUSSION}

The Angelchik device was introduced in 1979 [1]. It consisted of a C-shaped ring of silicon fitted around the gastroesophageal junction. The ring was secured in the place by means a fitted Dacron tape. It was well favored at the time compared to other anti-reflux surgeries

Jake Sloane ${ }^{1}$, Sanjay Gupta²

Affiliations: ${ }^{1}$ CT2 Surgical Trainee - BSc, MBChB, MRCS,

Core Surgical Trainee Year 2, General Surgical Department, Lister Hospital, Hertfordshire, UK; ${ }^{2} \mathrm{FRCS}$, Consultant Upper $\mathrm{Gl}$ and General Surgeon, General Surgical Department, Lister Hospital, Hertfordshire, UK. Corresponding Author: Mr. Jake Sloane, Flat 14 Crown Apartments, 45 Westholme Gardens, Ruislip, Middlesex, HA4 8QH, UK; Phone: +447956129103; E-mail: jakesloane@hotmail.com

Received: 22 January 2013

Accepted: 25 April 2013

Published: 01 July 2013

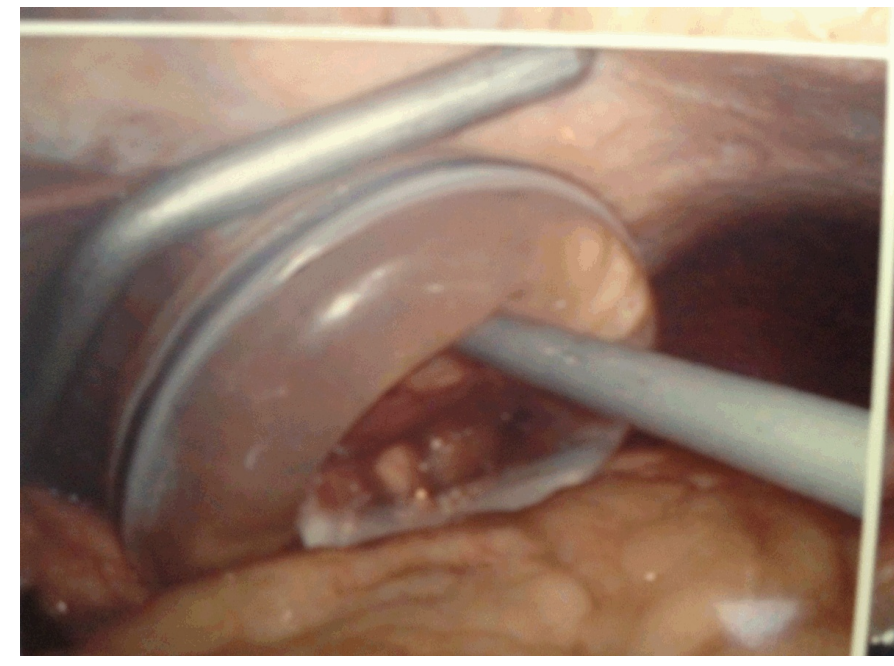

Figure 1: Laparoscopic image of the Angelchik device having been freed from the lower esophagus.

because of the simple and standardized technique of insertion of the device [2]. Over 25,000 devices were inserted worldwide [3].

However, enthusiasm for the device hugely subsided when long-term results became available. Up to $70 \%$ of patients developed moderate to severe dysphagia [4]. In addition, other complications were frequently reported including migration of device (due to Dacron tape failure) and erosion into surrounding structures [3].

\section{CONCLUSION}

By 1990, use of the Angelchik device was almost entirely abandoned and open Nissen's fundoplication became the accepted technique to treat GERD. Nowadays, the laparoscopic version of this procedure is common place.

Of note, a similar prosthesis to the Angelchik device is in use called the laparoscopic adjustable gastric band (also known as the lap-band or LAGB). However, rather than treating reflux, this implantable ring is employed in 
bariatric surgery to provide artificial satiety and improve weight loss. This clinical image report highlights the complications of a now rarely seen device.

$$
* * * * * * * * *
$$

Sloane J, Gupta S. A now rarely seen anti-reflux device: The Angelchik prosthesis. International Journal of Case Reports and Images 2013;4(7):399-400.

\section{$* * * * * * * * *$}

doi:10.5348/ijcri-2013-07-341-15

$* * * * * * * * *$

\section{Author Contributions}

Jake Sloane - Substantial contributions to conception and design, Acquisition of data, Analysis and interpretation of data, Drafting the article, Final approval of the version to be published

Sanjay Gupta - Substantial contributions to conception and design, Acquisition of data, Analysis and interpretation of data, Revising it critically for important intellectual content, Final approval of the version to be published

\section{Guarantor}

The corresponding author is the guarantor of submission.

\section{Conflict of Interest}

Authors declare no conflict of interest.

\section{Copyright}

(C) Jake Sloane et al. 2013; This article is distributed under the terms of Creative Commons attribution 3.0 License which permits unrestricted use, distribution and reproduction in any means provided the original authors and original publisher are properly credited. (Please see www.ijcasereportsandimages.com / copyright-policy.php for more information.)

\section{REFERENCES}

1. Angelchik JP, Cohen R. A new surgical procedure for the treatment of gastroesophageal reflux and hiatal hernia. Surgery Gynecology and Obstetrics 1979;148(2):246-8.

2. Crookes PF, DeMeester TR. The Angelchik prosthesis: What have we learned in fifteen years? Ann Thorac Surg 1994;57(6):1385-6.

3. Shetty VD, Thrumurthy SG, Pursnani KG, Ward JB, Mughal MM. Angelchik prosthesis with oesophageal adenocarcinoma: our surgical approach. Ann R Coll Surg Engl 2010;92(5):W64-8.

4. Mercer SJ, Toh SK, Somers SS. Esophageal adenocarcinoma developing above an Angelchik prosthesis. Dis Esophagus 2007;20(6):546-8.
Access full text article on other devices

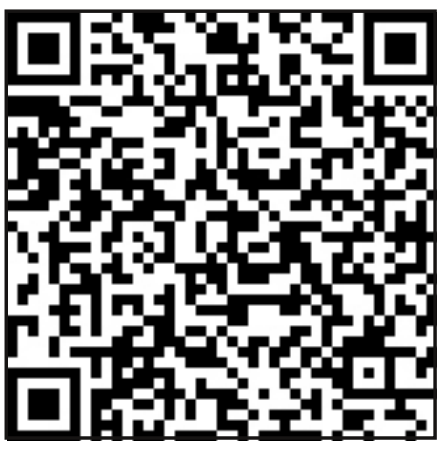

Access PDF of article on other devices

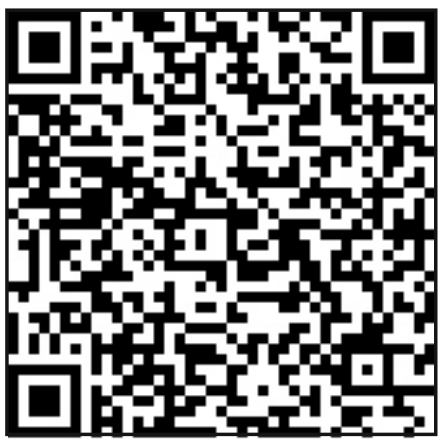

